\title{
Studies on the sandfly fauna (Diptera: Psychodidae: Phlebotominae) from transmission areas of American Cutaneous Leishmaniasis in state of Acre, Brazil
}

\author{
Alfredo CR Azevedo/ ${ }^{+}$, Simone M Costa, Maria CG Pinto', Janis L Souza ${ }^{1}$, Henrique C Cruz', \\ Joaquim Vidal', Elizabeth F Rangel
}

Laboratório de Transmissores de Leishmanioses, Instituto Oswaldo Cruz-Fiocruz, Av. Brasil 4365, 21040-900 Rio de Janeiro, RJ, Brasil

${ }^{1}$ Secretaria de Saúde do Estado do Acre, Rio Branco, AC, Brasil

Studies were undertaken on the phlebotomines in the municipalities of Bujari, Xapuri and Rio Branco in the state of Acre. The abundance of species on the ground and in the tree canopy was estimated by Standardized Index of Species Abundance. Of the 52 species identified, Lutzomyia (N.) antunesi, Lutzomyia (N.) whitmani, Lutzomyia (P.) davisi, Lutzomyia migonei, Lutzomyia (N.) umbratilis, Lutzomyia (N.) flaviscutellata, Lutzomyia (T.) ubiquitalis, Lutzomyia (P.) hirsuta hirsuta, Lutzomyia (P.) paraensis and Lutzomyia (P.) ayrozai are known to be vectors of Leishmania, the causative agent of American cutaneous leishmaniasis. Lutzomyia (T.) auraensis, Lu. (N.) antunesi, Lu. (N.) whitmani and Lu. (P.) davisi accounted for $66.95 \%$ of the specimens collected. Lu. (N.) whitmani was the most abundant species, followed by Lu. (N.) antunesi and Lu. (P.) davisi. Lu. (N.) antunesi was the most abundant species in the soil as well as in the canopy. Lu. (N.) umbratilis occurred in all three municipalities and was the fifth most abundant species in the Chico Mendes Municipal Park in Rio Branco. It was collected on both the ground level as well as in the canopy; however, it was more frequently collected in the tree canopy. The present study suggests the existence of three transmission cycles of Leishmania in Acre, including the transmission of Leishmania (V.) guyanensis by Lu. (N.) umbratilis south of the Amazon River.

Key words: Phlebotomine fauna - Lutzomyia - vector ecology - American Cutaneous Leishmaniasis - state of Acre - Brazil

American cutaneous leishmaniasis (ACL) is widely distributed in Latin America. In Brazil, the disease is regarded as an emerging infection and the prevalence of ACL is increasing as a result of the deforestation that occurs for the exploitation of natural resources, the expansion of agriculture and the construction of dams and hydroelectric projects. Within Brazil, ACL may present in a classic epidemiological pattern or as an epidemic surge associated with these activities (Lainson 1988, Rangel 1995, Rangel \& Lainson 2003, MS 2006). In an attempt to analyze the spatial distribution of the disease within Brazil, the National Leishmaniases Program of the Health Ministry has been analyzing disease circuit of ACL by associating the occurrence of human cases with specific socio-environmental variables (MS 2006).

Within this context, Amazonia has been identified as having an epidemiological circuit of rural and occupational variables that are associated with the destruction of forest. Within this region, the state of Acre has reported a large number of mucosal leishmaniasis cases. As reported by the Health Secretary of the state of Acre, the majority of patients were male $(72 \%)$ and over 10

Financial support: CNPq, MCT-CNPq/MS-SCTIE-DECIT-25/06, FIOCRUZ

+ Corresponding author: alcaraze@ioc.fiocruz.br

Received 15 April 2008

Accepted 13 November 2008 years of age (89\%). Moreover, from 1987-2007, the number of cases reported each year has increased and in this last year 1,100 cases were reported.

Recently, Tojal et al. $(2003,2006)$ characterized the Leishmania species isolated from the cutaneous lesions of patients in Rio Branco city, Leishmania (Viannia) braziliensis, Leishmania (V.) guyanensis, Leishmania $(V$.) lainsoni and a hybrid of Leishmania $(V$.) naiffi and L. (V.) lainsoni.

Studies on sandfly fauna in the state of Acre are still limited (Martins \& Silva 1964, Arias et al. 1984, SilvaNunes et al. 2008). This study aims to broaden the knowledge of phlebo-tomine fauna, detailing the species considered to be potential vectors in Acre and study aspects of their ecology.

\section{MATERIALS AND METHODS}

Study area - The state of Acre has a tropical wet and dry climate (Köppen classification) with yearly temperatures ranging from $24.5-32^{\circ} \mathrm{C}$. There are two very distinct seasons: a dry season and a wet season. During the dry season, which starts in March and extends through October, rain is absent, although the friagens (a local term for the cold fronts of polar origin that invade the Amazon) are particularly common. The rainy season, which is characterized by constant (daily) and abundant rain, is from November until April. The atmospheric humidity reaches $90 \%$ with pluviometric indexes ranging from 1,600-2,750 $\mathrm{mm}$ a year.

Sandfly collections - Collections were undertaken in the municipalities of Bujari (Area I, highway BR-364 km 
98), Xapuri (Area II, Barro Alto, Barra, Sibéria, Nazaré and Floresta) and Rio Branco (Area III, Chico Mendes Municipal Park, Area IV, highway BR-317 km 38, and Area V, highway AC-090 km 75) from 2002 through 2006. As suggested by the Health Secretary of the state of Acre, two of the locations (Bujari, Area I, and Rio Branco, Area III) were considered strategic areas for regular collections since these municipalities have been reported high incidences of human ACL cases.

Area $I$ is in the Bujari Municipality $\left(09^{\circ} 49^{\prime} 50^{\prime \prime} \mathrm{S}\right.$, $67^{\circ} 57^{\prime} 08^{\prime \prime} \mathrm{W}$ ), nearly $28 \mathrm{~km}$ from Rio Branco. The economy of Bujari is based on subsistence agriculture, cattle breeding, fish farming [e.g. tambaqui (Colossoma macropomum), curimatã (Prochilodus spp.) and pirarucu (Arapaima spp.)], rubber extraction (Hevea brasiliensis), chestnut production (Bertholletia excelsa), copaiba oil (Copaifera spp.) and the collection of wild seeds. Sandfly collections were conducted in the Antimari state forest with an area of 3,397.9 $\mathrm{km}^{2}$ ramal Espinhara [(highway BR-364 km 98)], where there is wood extraction.

Rio Branco Municipality (0958'29”S, 6748’36”W), Area III: Chico Mendes Municipal Park is located on highway AC-040 $10 \mathrm{~km}$ from the city of Rio Branco. The park occupies an area of 52 ha and is considered one of the last remaining areas of primary forest where very important representative species of fauna and flora live: chestnut trees, rubber trees, the squirrel-monkey (Saimiri boliviensis), the saki (Pithecia irrorata), the owl-monkey (Aotus nigriceps), the tamarin (Saguinus labiatus), the paca (Agouti paca), the squirrel (Sciurus spp.), sloths (Bradypus variegatus, Choloepus didactylus and Choloepus hoffmanni), the boa (Boa constrictor), the liana (Chironius bicarinatus) and several species of lizards and birds.

Sandfly capture and identification - The phlebotomines were collected in forested areas impacted by man (Area I) and in a park (Area III), using CDC light traps. Ground level captures $(50 \mathrm{~cm}$ high) were made in Areas I and III, as well as in the tree canopy (15-18 m) in Area III. Eight CDC light traps were mounted (ground and/ or canopy) at different times between 17:00 h and 21:00h providing a total of $17 \mathrm{~h}$ capture per trap. Forty sandfly collections were carried out during the months of February/April and August/October from 2003-2006. The methods of collection used in areas II, IV and V; however collections at these areas were performed only eventually to describe local sandfly fauna in comparison to areas I and III (during the period of 2002 and 2003) were identical to those applied in areas I and III. The sandfly specimens were mounted individually on slides and the identification of species followed the classification proposed by Young and Duncan (1994). The specimens of the Oswaldoi group were identified according to Galati (2003).

Statistical analysis - The Index of Species Abundance (ISA), Standardized Index of Species Abundance (SISA) (Roberts \& Hsi 1979) and Shannon-Wiener Diversity Index (Shannon 1948) were used to analysis the data obtained in Areas I and III. The ISA values were determined using Excel 2002 (Microsoft) and were converted in SISA, to values between 0-1. In order to obtain the Shannon-Wiener Diversity Index, the DivEs software (WC Rodrigues) was used.

Natural infection - Some sandflies collect in Areas I and III were analyzed for natural infection by flagellates. The female sandfly guts were dissected in sterile PBS. If flagellates were observed in the gut, they were inoculated into the hind paws of Syrian hamsters (Mesocriscetus auratus; CEUA number P0097-01). Simultaneously, the sandfly species was identified by analysis of the spermathecae.

\section{RESULTS}

Sandfly fauna - A total of 7,302 specimens belonging to 52 species were collected in the five areas. Of these 16 are here registered for the state of Acre for the first time. Overall, $66.9 \%$ of the specimens collected were identified as Lutzomyia (Trichophoromyia) auraensis, Lutzomyia (N.) antunesi, Lutzomyia (N.) whitmani and Lutzomyia (P.) davisi. Some of the identified sandfly species are vectors of Leishmania species: $L u$. (N.) whitmani, Lu. (N.) antunesi, Lu. (P.) davisi, Lutzomyia (N.) umbratilis, Lutzomyia (N.) flaviscutellata, Lutzomyia (T.) ubiquitalis (in Area II only), Lutzomyia (P.) hirsuta hirsuta, Lutzomyia migonei (Group Migonei), Lutzomyia (P.) paraensis and Lutzomyia (P.) ayrozai (Table I). A total of $915 \mathrm{~h}$ (Area I, $255 \mathrm{~h}$; Area II, $210 \mathrm{~h}$; Area III, $360 \mathrm{~h}$; Area IV, $30 \mathrm{~h}$ and Area V, 60 h) were spent in captures. The best results were obtained in Area II, corresponding to 9.1 specimens per hour. In Areas I and III, 7.8 specimens per hour were observed.

Statistical tests were applied to 4,805 collected specimens, obtained during the $615 \mathrm{~h}$ of capture in Areas I and III. Lu. (N.) whitmani was the most abundant species with a SISA of 0.718. The SISA for other Leishmania sandfly vectors were: $L u$. (N.) antunesi, $0.670 ; L u$. (P.) davisi, 0.664; Lu. (N.) umbratilis, 0.374; Lu. (P.) h. hirsuta, 0.136; Lu. (N.) flaviscutellata, 0.118; Lu. migo$n e i, 0.074 ;$ Lu. (P.) paraensis, 0.030 and Lu. (P.) ayrozai, 0.025 (Table II). Overall, these sandfly species accounted for $75.5 \%$ of the specimens collected.

Subgenera Nyssomyia (54.5\%) and Psychodopygus (30.4\%) species accounted for $84.9 \%$ of sandflies collected in Areas I and III (Table II). Lu. davisi, Lutzomyia carrerai carrerai, Lutzomyia amazonensis, Lutzomyia chagasi and Lu. h. hirsuta (subgenus Psychodopygus) accounted for $67 \%$ of the sandfly fauna in Area I, while Lu. whitmani, Lu. antunesi, Lu. umbratilis, Lutzomyia richardwardi and Lu. flaviscutellata (subgenus Nyssomyia) accounted for $86.4 \%$ in Area III (Fig. 1).

The highest number of sandfly species (34) was collected in Area I and as a result, Area I had the highest value for the Shannon-Wiener Diversity Index (0.90).

The species with the highest SISA values that were common to both areas were $L u$. (P.) davisi (Area I SISA 0.792, Area III SISA 0.542), Lu. (N.) antunesi (Area I SISA 0.475, Area III SISA 0.801), Lu. (N.) whitmani (Area I SISA 0.686, Area III SISA 0.729), Lu. (Lutzomyia) gomezi (Area I SISA 0.372, Area III SISA 0.280). 
TABLE I

Total and percentage of sandfly species collected in the Area I (Bujari municipality), Area II (Xapuri municipality), Areas III, IV, V (Rio Branco municipality), state of Acre, Brazil, 2002-2006

\begin{tabular}{|c|c|c|c|c|}
\hline Species & Males & Females & Total & $\%$ \\
\hline Lutzomyia (Trichophoromyia) auraensis & 695 & 724 & 1,419 & 19.44 \\
\hline Lutzomyia (Nyssomyia) antunesi ${ }^{c}$ & 693 & 632 & 1,325 & 18.16 \\
\hline Lutzomyia (N.) whitmanic & 821 & 347 & 1,168 & 16.00 \\
\hline Lutzomyia (Psychodopygus) davisic & 470 & 505 & 975 & 13.35 \\
\hline Lutzomyia (P.) carrerai carrerai & 165 & 312 & 477 & 6.53 \\
\hline Lutzomyia nevesi (Group Verrucarum) & 112 & 119 & 231 & 3.16 \\
\hline Lutzomyia (N.) umbratilis ${ }^{c}$ & 123 & 97 & 220 & 3.01 \\
\hline Lutzomyia (P.) hirsuta hirsuta ${ }^{c}$ & 110 & 106 & 216 & 2.96 \\
\hline Brumptomyia spp. $^{a}$ & 100 & 60 & 160 & 2.19 \\
\hline Lutzomyia saulensis (Group Saulensis) & 22 & 121 & 143 & 1.96 \\
\hline Lutzomyia (N.) richardwardi & 25 & 101 & 126 & 1.73 \\
\hline Lutzomyia (Pressatia) choti & 83 & 32 & 115 & 1.57 \\
\hline Lutzomyia (Lutzomyia) sherlocki & 27 & 40 & 67 & 0.92 \\
\hline Lutzomyia (N.) shawi ${ }^{b}$ & 21 & 41 & 62 & 0.85 \\
\hline Lutzomyia (Lutzomyia) gomezi & 9 & 51 & 60 & 0.82 \\
\hline Lutzomyia (Sciopemyia) sordellii & 26 & 33 & 59 & 0.81 \\
\hline Lutzomyia (N.) flaviscutellatac & 13 & 35 & 48 & 0.66 \\
\hline Lutzomyia (P.) amazonensis & 29 & 12 & 41 & 0.56 \\
\hline Lutzomyia (Trichophoromyia) ubiquitalis ${ }^{c}$ & 27 & 14 & 41 & 0.56 \\
\hline Lutzomyia (P.) lainsoni ${ }^{b}$ & 5 & 33 & 38 & 0.52 \\
\hline Lutzomyia (Evandromyia) infraspinosa ${ }^{b}$ & 4 & 31 & 35 & 0.48 \\
\hline Lutzomyia (Psathyromyia) shannoni & 2 & 27 & 29 & 0.40 \\
\hline Lutzomyia (S.) preclara ${ }^{b}$ & 2 & 25 & 27 & 0.37 \\
\hline Lutzomyia walkeri (Group Migonei) & 15 & 9 & 24 & 0.33 \\
\hline Lutzomyia baculus (Group Migonei) & 8 & 15 & 23 & 0.31 \\
\hline Lutzomyia serrana (Group Verrucarum) & 5 & 14 & 19 & 0.26 \\
\hline Lutzomyia (P.) chagasi ${ }^{b}$ & 18 & - & 24 & 0.25 \\
\hline Lutzomyia migoneic (Group Migonei) & 8 & 9 & 17 & 0.23 \\
\hline Lutzomyia (P.) dendrophyla & 13 & 3 & 16 & 0.22 \\
\hline Lutzomyia peresi ${ }^{b}$ (Group Oswaldoi) & - & 15 & 15 & 0.21 \\
\hline Lutzomyia (Trichopygomyia) dasypodogeton ${ }^{b}$ & 13 & 1 & 14 & 0.19 \\
\hline Lutzomyia (Vinnamyia) furcata & 8 & 5 & 13 & 0.18 \\
\hline Lutzomyia (P.) paraensis ${ }^{b}$ & 1 & 8 & 9 & 0.12 \\
\hline Lutzomyia (P.) damascenoi & - & 7 & 7 & 0.10 \\
\hline Lutzomyia (P.) yulli yulli ${ }^{b}$ & 2 & 5 & 7 & 0.10 \\
\hline Lutzomyia (P.) ayrozai ${ }^{b}$ & 3 & 3 & 6 & 0.08 \\
\hline Lutzomyia sericea (Group Migonei) & 2 & 4 & 6 & 0.08 \\
\hline Lutzomyia aragaoi (Group Aragaoi) & 2 & 2 & 4 & 0.05 \\
\hline Lutzomyia (N.) olmeca bicolor & - & 4 & 4 & 0.05 \\
\hline Lutzomyia (P.) lutziana & 2 & 1 & 3 & 0.04 \\
\hline B. avellari & 1 & 1 & 2 & 0.03 \\
\hline Lutzomyia (P.) corossoniensis ${ }^{b}$ & 2 & - & 2 & 0.03 \\
\hline Lutzomyia (P.) llanosmartinsi ${ }^{b}$ & - & 2 & 2 & 0.03 \\
\hline Lutzomyia (Micropygomyia) micropyga & 1 & 1 & 2 & 0.03 \\
\hline Lutzomyia (E.) bourrouli & 1 & - & 1 & 0.01 \\
\hline Lutzomyia (T.) elegans & 1 & - & 1 & 0.01 \\
\hline Lutzomyia (T.) ininii ${ }^{b}$ & 1 & - & 1 & 0.01 \\
\hline Lutzomyia (E.) monstruosa & - & 1 & 1 & 0.01 \\
\hline Lutzomyia pilosa $^{b}$ (Group Pilosa) & 1 & - & 1 & 0.01 \\
\hline Lutzomyia (P.) punctigeniculata & - & 1 & 1 & 0.01 \\
\hline Lutzomyia villelai ${ }^{b}$ (Group Oswaldoi) & - & 1 & 1 & 0.01 \\
\hline Total & 3,692 & 3,610 & 7,302 & 100.00 \\
\hline
\end{tabular}

$a: B$. brumpti and B. pentacantha; $b$ : species cited by the 1 st time in the state of Acre; $c$ : sandfly vectors of American cutaneous leishmaniasis. 
TABLE II

Total, percentage, specimens dissected and SISA of the sand fly species collected at Areas I (Bujari municipality) and III (Rio Branco municipality), state of Acre, Brazil, 2003-2006

\begin{tabular}{|c|c|c|c|c|c|c|}
\hline Species & Males & Females (Dissected) & Total & $\%$ & SISA & Rank \\
\hline Lutzomyia (Nyssomyia) whitmani ${ }^{b}$ & 810 & $310(192)$ & 1,120 & 23.32 & 0.718 & 1 st \\
\hline Lutzomyia (N.) antunesi ${ }^{b}$ & 658 & $577(286)$ & 1,235 & 25.70 & 0.670 & 2nd \\
\hline Lutzomyia (Psychodopygus) davisi ${ }^{b}$ & 376 & $436(56)$ & 812 & 16.90 & 0.664 & $3 \mathrm{rd}$ \\
\hline Brumptomyia spp. $^{a}$ & 86 & $59(32)$ & 145 & 3.02 & 0.436 & 4 th \\
\hline Lutzomyia (Nyssomyia) umbratilis ${ }^{b}$ & 122 & $94(32)$ & 216 & 4.50 & 0.374 & 5 th \\
\hline Lutzomyia (Lutzomyia) gomezi & 9 & $46(23)$ & 55 & 1.14 & 0.341 & 6 th \\
\hline Lutzomyia nevesi (Group Verrucarum) & 95 & $73(54)$ & 168 & 3.50 & 0.324 & 7 th \\
\hline Lutzomyia (Lutzomyia) sherlocki & 23 & $34(11)$ & 57 & 1.19 & 0.245 & 8 th \\
\hline Lutzomyia (P.) carrerai carrerai & 152 & $264(43)$ & 416 & 8.66 & 0.245 & \\
\hline Lutzomyia saulensis (Group Saulensis) & 12 & $53(8)$ & 65 & 1.35 & 0.194 & 10th \\
\hline Lutzomyia (Sciopemyia) preclara & 2 & 25 & 27 & 0.56 & 0.145 & 11th \\
\hline Lutzomyia (P.) hirsuta hirsuta ${ }^{b}$ & 105 & $95(12)$ & 200 & 4.16 & 0.136 & 12 th \\
\hline Lutzomyia (Trichophoromyia) auraensis & 13 & $23(13)$ & 36 & 0.75 & 0.127 & 13th \\
\hline Lutzomyia (Trichopygomyia) dasypodogeton & 11 & 1 & 12 & 0.25 & 0.122 & 14 th \\
\hline Lutzomyia (N.) flaviscutellata & 1 & $22(2)$ & 23 & 0.48 & 0.118 & 15 th \\
\hline Lutzomyia (Evandromyia) infraspinosa & 4 & $16(10)$ & 20 & 0.42 & 0.116 & 16th \\
\hline Lutzomyia (Vinnamyia) furcata ${ }^{b}$ & 8 & $5(2)$ & 13 & 0.27 & 0.114 & 17 th \\
\hline Lutzomyia (Psathyromyia) shannoni & 1 & $12(11)$ & 13 & 0.27 & 0.106 & 18th \\
\hline Lutzomyia (N.) shawi & 4 & $9(2)$ & 13 & 0.27 & 0.093 & 19th \\
\hline Lutzomyia (P.) dendrophyla & 10 & 2 & 12 & 0.25 & 0.082 & 20 th \\
\hline Lutzomyia baculus (Group Migonei) & 2 & $5(4)$ & 7 & 0.15 & 0.076 & 21th \\
\hline Lutzomyia migonei (Group Migonei) ${ }^{b}$ & 7 & $2(1)$ & 9 & 0.19 & 0.074 & 22 th \\
\hline Lutzomyia (S.) sordellii & 7 & $29(2)$ & 36 & 0.75 & 0.066 & 23th \\
\hline Lutzomyia walkeri (Group Migonei) & 12 & 6 & 18 & 0.37 & 0.061 & 24 th \\
\hline Lutzomyia peresi (Group Oswaldoi) & - & $10(10)$ & 10 & 0.21 & 0.058 & 25 th \\
\hline Lutzomyia (N.) richardwardi & 1 & $8(5)$ & 9 & 0.19 & 0.055 & 26th \\
\hline Lutzomyia (Pressatia) choti & 3 & 3 & 6 & 0.12 & 0.053 & 27 th \\
\hline Lutzomyia serrana (Group Verrucarum) & 1 & 4 & 5 & 0.10 & 0.037 & 28th \\
\hline Lutzomyia aragaoi (Group Aragaoi) & 2 & 1 & 3 & 0.06 & 0.031 & 29th \\
\hline Lutzomyia (N.) olmeca bicolor & - & $4(2)$ & 4 & 0.08 & 0.031 & 30 th \\
\hline Lutzomyia (P.) paraensis ${ }^{b}$ & 1 & 8 & 9 & 0.19 & 0.030 & 31 th \\
\hline Lutzomyia (P.) ayrozai $i^{b}$ & 2 & - & 2 & 0.04 & 0.025 & 32 th \\
\hline Lutzomyia sericea (Group Migonei) & 2 & - & 2 & 0.04 & 0.024 & 33th \\
\hline Lutzomyia (P.) chagasi & - & 17 & 17 & 0.35 & 0.022 & 34 th \\
\hline Lutzomyia (P.) amazonensis & 2 & - & 2 & 0.04 & 0.020 & 35 th \\
\hline Lutzomyia (P.) lutziana & 2 & - & 2 & 0.04 & 0.017 & 36th \\
\hline Lutzomyia (P.) corossoniensis & 2 & - & 2 & 0.04 & 0.016 & 37 th \\
\hline Lutzomyia (E.) monstruosa & - & 1 & 1 & 0.02 & 0.015 & 38 th \\
\hline Lutzomyia villelai (Group Oswaldoi) & - & 1 & 1 & 0.02 & 0.014 & 40th \\
\hline Lutzomyia (T.) ininii & 1 & - & 1 & 0.02 & 0.013 & 41th \\
\hline Lutzomyia (E.) bourrouli & 1 & - & 1 & 0.02 & 0.011 & 42th \\
\hline Total & 2,550 & $2,255(813)$ & 4,805 & 100.00 & & \\
\hline
\end{tabular}

$a$ : B. brumpti and B. pentacantha; $b$ : sand fly vectors of American cutaneous leishmaniasis; SISA: Standardized Index of Species Abundance.

Overall, Lu. (P.) davisi (0.790) and Lu. (N.) antunesi (0.801) were the most abundant in Areas I and III, respectively (Fig. 2A, B).

The ranking of sandfly species that serve as vectors for Leishmania registered from areas I and III is shown in Fig. 3. Lu. (N.) antunesi, Lu. (N.) whitmani, Lu. (N.) umbratilis, Lu. (P.) davisi, Lu. (N.) flaviscutellata and Lu. migonei were collected in Areas I and III; Lu. (P.) paraensis and $L u$. (P.) ayrozai were collected only in Area III and $L u$. (P.) $h$. hirsuta was collected only in Area I. $L u$. (N.) antunesi was the most abundant species in Area III (0.801), followed by $L u$. (N.) whitmani (0.729) and Lu. (N.) umbratilis (0.573). In Area I, Lu. (P.) davisi was the most abundant (0.792). Fig. 4A shows the stratification of the most representative sandfly species. $L u$. (N.) whitmani was the most numerous in the canopy 


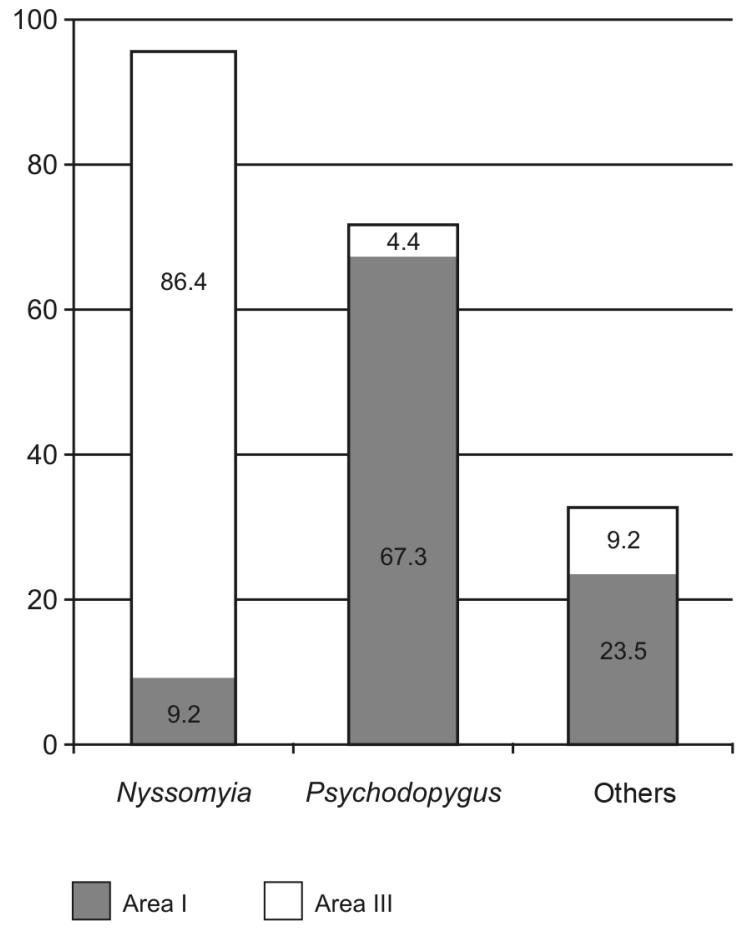

Fig. 1: species percentage of Nyssomyia and Psychodopygus subgenera in Areas I (Bujari municipality) and III (Rio Branco municipality), state of Acre, Brazil, 2003-2006.

A
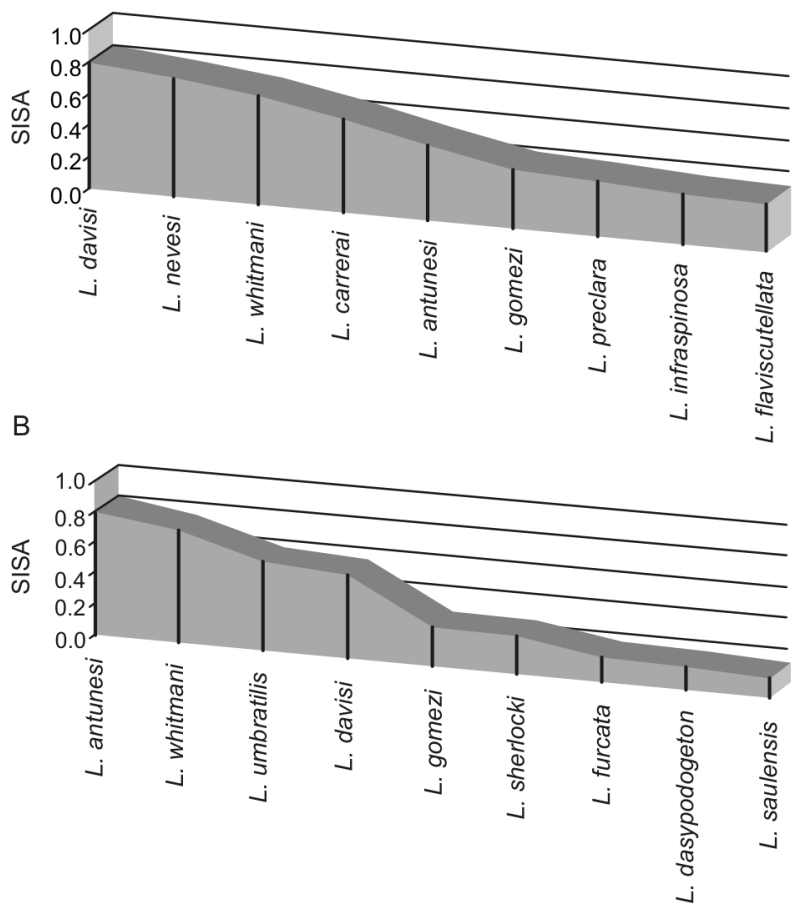

Fig. 2: Sandardized Index of Species Abundance (SISA) of the nine abundant species in Areas I (Bujari municipality) and III (Rio Branco municipality), state of Acre, Brazil,2003-2006. A: Area I; B: Area III.

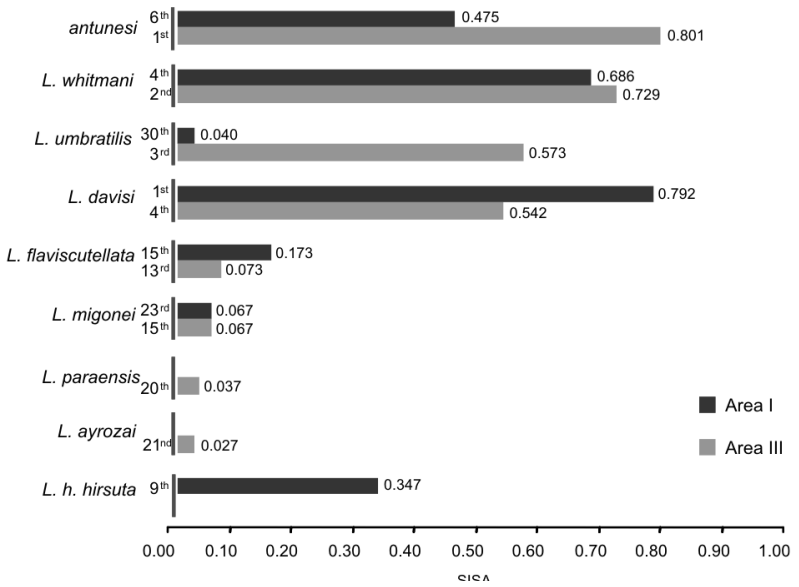

Fig. 3: Standardized Index of Species Abundance (SISA) and rank of medical important species in Areas I (Bujari municipality) and III (Rio Branco municipality), state of Acre, Brazil, 2003-2006.
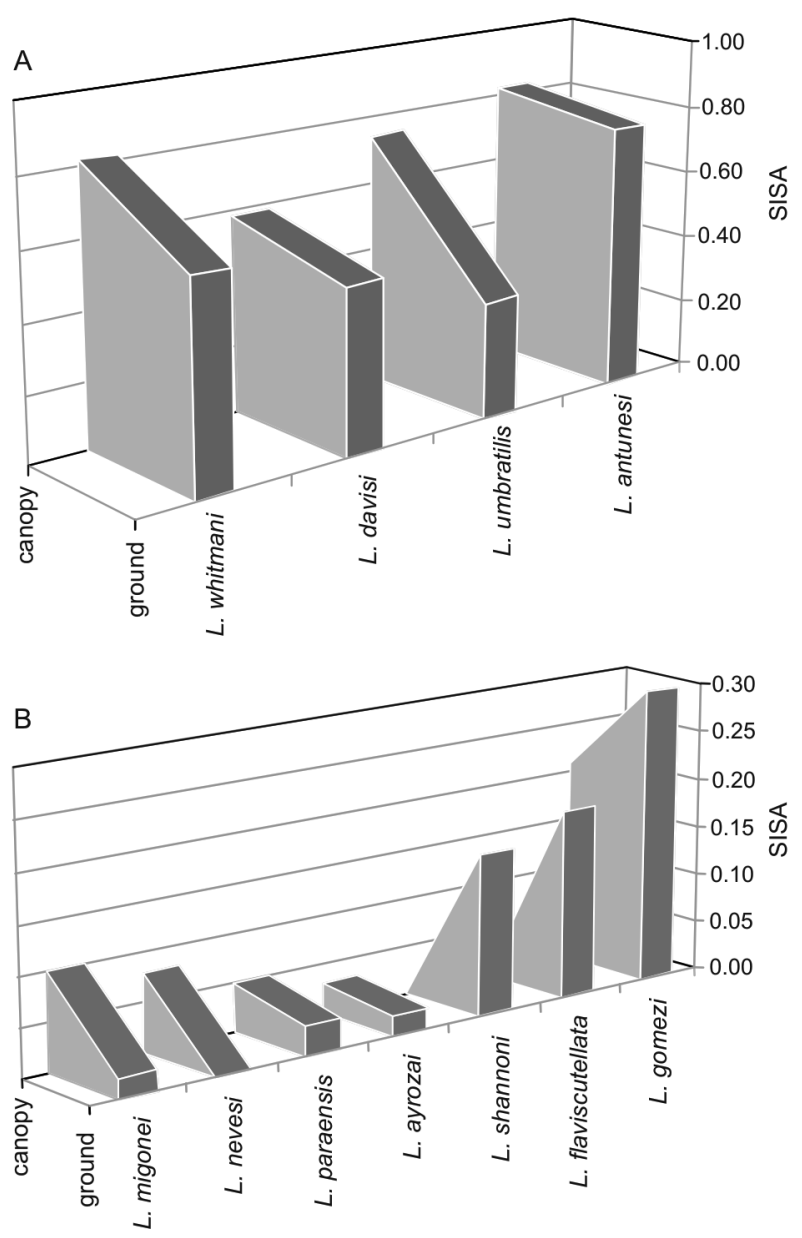

Fig. 4: Standardized Index of Species Abundance (SISA) on the ground and in the tree canopy, in Area III (Rio Branco municipality), state of Acre, Brazil, 2003-2006. A: species with highest values of SISA; B: other species. 
(0.816), while $L u$. (N.) antunesi had the highest SISA value in the canopy (0.821). $L u$. (N.) umbratilis was more abundant in canopy (0.740), compared to the ground level collections (0.343). Less representative species, namely Lu. (N.) flaviscutellata (0.193) and Lutzomyia (Psathyromyia) shannoni (0.164) were collected in ground level traps only, while Lutzomyia nevesi (Group Verrucarum) was only collected in the canopy (0.079) (Fig. 4B).

Natural infection - A total of 816 females belonging to 23 sandfly species were dissected. It was impossible to identify 12 Brumptomyia specimens, since Brumptomyia brumpti and Brumptomyia avellari females cannot be distinguished morphologically. $L u$. (N.) antunesi and $L u$. (N.) whitmani were the predominant species and in one specimen of each a natural infection of flagellates, probably Peripylarian promastigotes, in the pylorus and mid gut was observed. The flagellates were inoculated into hamsters but no lesion was observed and the characterization of the parasite was enabling.

\section{DISCUSSION}

The state of Acre is characterized by a great variety of ecosystems and habitats and it is rich in vegetation typologies, topographical gradients and different types of soils (IBGE 1996). Although $45.6 \%$ of its territory is occupied by protected areas, the state has been undergoing continuous deforestation, which has affected $19,200 \mathrm{~km}^{2}$ (Souza Jr. et al. 2006). This deforestation occurs mostly for new agricultural settlements, constant slash and burn and extraction of timber for commercial purposes. Since 2002 , a $34 \%$ increase in the annual deforestation rate has been observed for the whole state $\left(878 \mathrm{~km}^{2}\right.$ a year). Among the municipalities that have lost their original forest cover, the most significant are Bujari (34\%) and Rio Branco (25\%) (Souza Jr. et al. 2006). Located in south-western Amazonia, the state of Acre sandfly fauna is typical to the Amazon region.

Among the total number of species present in the five areas, 16 species have not yet been registered in the state of Acre by Young and Duncan (1994), Aguiar and Medeiros (2003) or Galati (2003). Among the newly registered species were $L$. (P.) paraensis and $L$. (P.) ayrozai, both of which are of significant medical and epidemiological importance in the Amazon region. Although the females of B. brumpti (first occurrence) and Brumptomyia pentacanth $a$ are indistinguishable, and were therefore just classified as Brumptomyia, the identification of both species was possible due to the 92 male specimens of $B$. brumpti and the eight specimens of $B$. pentacantha found in the area. The identification of $L u$. peresi and Lutzomyia villelai was possible by using the taxonomic key proposed by Galati (2003). Even though Young and Ducan (1994) described Lu. villelai as similar species to Lutzomyia trinidadensis, and previous studies have detected $\mathrm{Lu}$. trinidadensis in the state of Acre, the species found in this study is in fact Lu. villelai as it lacks developed spines in the pharynges, an important morphological feature that distinguishes this species from $L u$. trinidadensis.

The Psychodopygus and Nyssomyia subgenera are the most abundant species and also the most important vectors of Leishmania in the Amazon Region (Ward et al. 1973, Grimaldi et al. 1991, Rangel \& Lainson 2003) and this was confirmed in the present study. The species of the Nyssomyia subgenus, in particular Lu. antunesi and $\mathrm{Lu}$. whitmani, were predominant in Area III (Chico Mendes Municipal Park), which, despite being a protected park, is under significant human pressure from both the new dwelling areas and deforestation activities now surrounding the park, as well as the approximately 96,000 people per year who use area for recreation (JO Guimarães, park manager, personal communication). By contrast, Area I (ramal Espinhara) contained the highest frequency of species of the Psychodopygus subgenus. The predominance of the Psychodopygus subgenus, in addition to a higher Shannon-Wiener index of diversity value (0.90), are indications of a more preserved vegetation in Area I, which could be more structured in relation to Chico Mendes Municipal Park (Area III).

In confirmation of previous studies, this study suggests that changes to the forest have a profound impact on the composition and behaviour of the sandfly fauna (Arias \& Freitas 1982, Ready et al. 1986, Azevedo et al. 2002). Azevedo et al. (2002) demonstrated that, based on the quantitative and qualitative analysis of the sandfly fauna in the Peixoto de Azevedo municipality (state of Mato Grosso), differences in the composition of the sandfly fauna between the primary forest (predominantly Psychodopygus) and the anthropic area (preimarily Nyssomyia) could be detected. In the areas studied in the state of Acre, nine potential Leishmania vectors were identified in Areas I and III. Among them, Lu. (N.) whitmani, Lu. (N.) antunesi, $L u$. (P.) davisi and $L u$. (N.) umbratilis are the most important due to their higher SISA values.

$L u$. (N.) umbratilis is the most important vector of $L$. (V.) guyanensis, an etiological agent of ACL, which is characterized by multiple lesions (Ward \& Fraiha 1977). Different studies have demonstrated the epidemiological importance of this species in the area north of the Amazon River, in the states of Pará (Lainson et al. 1976, 1979, 1981), and Amazonas, Brazil (Arias \& Freitas 1977, 1978, Arias et al. 1981), in French Guiana (Gentile et al. 1981, Pajot et al. 1982) and in Ve-nezuela (Feliciangeli et al. 1985).

In all studies, the behavioural pattern of $L u$. (N.) umbratilis is similar when compared to the areas evaluated here. This species is abundant and anthropophilic. Its preferred habitats are buttress roots, trunks and the tree canopy where it feeds on sloth. It is active during the twilight hours, although it may also bite during the first hours of the day (Rangel \& Lainson 2003). The fact that $L u$. (N.) umbratilis can be found infected with $L$. (V.) guyanensis exclusively in the area north of the Amazon River has raised doubts regarding the real taxonomy of this species. Arias and Freitas (1978) suggested that the Amazon River could function as a geographic barrier to the transmission of L. (V.) guyanensis. Furthermore, Lainson (1988) suggested that $L u$. (N.) umbratilis could represent a complex of species, since it has not been observed transmitting $L$. (V.) guyanensis south of the Amazon River, perhaps due to the different behaviour between the northern 
and southern populations of this species. While working in the municipality of Peixoto de Azevedo (an area with endemic cutaneous leishmaniasis), Azevedo et al. (2002) observed that $L u$. (N.) umbratilis was one of the most abundant and anthropophilic sandfly species. The same study demonstrated the association of $L u$. (N.) umbratilis with $L$. $(V$.) braziliensis as it was found in a naturally infected $L u$. (N.) umbratilis specimen.

The studies carried out at Chico Mendes Municipal Park (Area III) revealed the presence of $L u$. $(N)$ umbratilis within two different strata, although $L u$. $(N)$ umbratilis was predominantly isolated in the tree canopy. In the tree canopy, $L u$. (N.) umbratilis was the third most abundant species among all other collected sandflies. It is important to note that the vertebrate park fauna is composed of mammals belonging to the Xenarthra, Rodentia, Didelphimorphia and Primates orders. Among Xenarthra, the Conservation Unit inventory (JO Guimarães, personal communication) described three species of sloths including $C$. didactylus, a reservoir of L. (V.) guyanensis. In addition to the characterization of Leishmania isolated from patients in the municipality of Rio Branco (Tojal et al. 2006), the presence of $L u$. (N.) umbratilis in the tree canopy and the presence of a natural reservoir of $L$. (V.) guyanensis within the areas studied provide strong evidence of the existence of a transmission cycle of $L$. (V.) guyanensis by $L u$. (N.) umbratilis. Therefore, the evidence presented in this paper does not support the hypothesis of a possible $L u$. (N) umbratilis complex in the region. The transmission of L. (V.) guyanensis by this sandfly species south of the Amazon River, even though the vector's behaviour is similar to that previously reported in literature, has been suggested for the first time.

According to the state of Acre's Health Secretary, and taking into consideration the findings of Tojal et al. (2006), most human cases of ACL in the region seem to be related to $L$. $(V$.) braziliensis infection. Given the frequency of $L$. (V.) braziliensis and its spatial distribution across the transmission areas, in addition to the fact that no known $L$. (V.) braziliensis vectors, such as Lutzomyia (P.) wellcomei and Lutzomyia (P.) complexa, were detected from Northern Brazil, $L u$. (N.) whitmani could be a Leishmania vector for the municipalities investigated during the present study. Importantly, previous studies have connected $L u$. (N.) whitmani with the transmission of Leishmania (V.) shawi in the Amazon region (Rangel et al. 1996, Lainson \& Shaw 1998, Rangel \& Lainson 2003, Costa et al. 2007).

In agreement with Tojal et al. (2006), who have isolated and characterized $L$. (V.) lainsoni from Acre's patients, and supported by the data presented in this study, the finding of $L u$. (T.) ubiquitalis suggests that the transmission cycle in the state of Acre is similar to the transmission cycle reported for the state of Pará (Silveira et al. 1991, Lainson \& Shaw 1998, Rangel \& Lainson 2003). Furthermore, a previous report has already demonstrated the presence of $L u$. (T.) ubiquitalis in the Acrelândia municipality and suggested that this sandfly species is a local vector of Leishmania (Silva-Nunes et al. 2008).

\section{ACKNOWLEDGEMENTS}

To Joseline de Oliveira Guimarães (Chico Mendes Municipal Park), for support during the sandfly collections in the park, to Margarete Martins Afonso (IOC), for technical help, to Diamar da Costa-Pinto (IOC) and Cláudio Roberto Valente Meneses (University of California at Davis), for some suggestions in the text, and to Iorlando Barata (Instituto Evandro Chagas, Fundação Nacional de Saúde, Belém, Pará), for cooperation during the field work.

\section{REFERENCES}

Aguiar GM, Medeiros WM 2003. Distribuição regional e habitats das espécies de flebotomíneos do Brasil. In Flebotomíneos do Brasil. EF Rangel, R Lainson (eds.), Fiocruz, Rio de Janeiro, p. 207-255.

Arias JR, Freitas RA 1977. Flebotomíneos da Amazônia central do Brasil. 1. Resultados obtidos das capturas feitas em isca humana e eqüina. (Diptera: Psychodidae). Acta Amazônica 7: 507-527.

Arias JR, Freitas RA 1978. Sobre os vectores da leishmaniose cutânea na Amazônia central do Brasil. 2. Incidência de flagelados em flebotomíneos selváticos. Acta Amazônica 8: 387-396.

Arias J, Freitas RA 1982. The known geographical distribution of sandflies in state of Acre, Brasil (Diptera: Psychodidae). Acta Amazônica 12: 401-408.

Arias JR, Freitas RA, Barrett TV 1984. A new sandfly in the subgenus Nyssomyia (Diptera, Psychodidae) from the Amazon Basin of Brazil. Mem Inst Oswaldo Cruz 79: 325-327.

Arias JR, Naiff RD, Miles MA, Souza AA 1981. The opossum Didelphis marsupialis (Marsupialia: Didelphidae) as a reservoir host of Leishmania braziliensis guyanensis in the Amazon Basin of Brazil. Trans R Soc Trop Med Hyg 75: 537-541.

Azevedo ACR, Lainson R, Souza AA, Fé NF, Feliciangeli DM, Meneses CRV, Rangel EF 2002. Comparative studies of populations of Lutzomyia umbratilis (Diptera: Psychodidae) in Brazil and Venezuela. J Med Entomol 39: 587-600.

Costa SM, Cechinel M, Bandeira V, Zannuncio JC, Lainson R, Rangel EF 2007. Lutzomyia (Nyssomyia) whitmani s.l. (Antunes \& Coutinho 1939) (Diptera: Psychodidae: Phlebotominae): geographical distribution and the epidemiology of American Cutaneous Leishmaniasis in Brazil. Mini-review. Mem Inst Oswaldo Cruz 102: 149-153.

Feliciangeli MD, Pérez JR, Ramirez A 1985. First Venezuelan record of Lutzomyia umbratilis Ward \& Fraiha 1977 (Diptera: Psychodidae), a proven vector of Leishmania braziliensis guyanensis. Trans R Soc Trop Med Hyg 79: 878.

Galati EAB 2003. Morfologia e Taxonomia. In Flebotomíneos do Brasil. EF Rangel, R Lainson (eds.), Fiocruz, Rio de Janeiro, p. 23-175.

Gentile B, Le Pont F, Pajot FX, Besnard R 1981. Dermal leishmaniasis in French Guiana: the sloth (Choloepus didactylus) as reservoir host. Trans Roy Soc Trop Med Hygiene 75: 612-613.

Grimaldi G Jr, Momen H, Naiff RD, McMahon-Pratt D, Barret TV 1991. Characterization and classification of leishmanial parasites from human, wild mammals and sandflies in the Amazon region of Brazil. Am J Trop Med Hyg 44: 645-661.

IBGE - Instituto Brasileiro de Geografia e Estatística 1996. Anuário Estatístico do Brasil, Departamento de Editoração e Gráfica, Rio de Janeiro, p. 8-32.

Lainson R 1988. Ecological interactions in the transmission of the leishmaniasis. Philos Trans R Soc Lond Serie B 321: 389-404.

Lainson R, Shaw JJ 1998. New Word Leishmaniasis the neotropical 
Leishmania species. In A Ballows \& M Sussman (eds), Microbiology and Microbial Infections, L Topley and Wilson's Collier, London, p. 241-266.

Lainson R, Shaw JJ, Ready PD, Miles MA, Póvoa M 1981. Leishmaniasis in Brazil: XVI isolation and identification of Leishmania species from sandflies wild mammals and man in north Pará State with particular reference to $L$. braziliensis guyanensis agent of "pian-bois". Trans R Soc Trop Med Hyg 75: 530-536.

Lainson R, Shaw JJ, Ward RD, Ready PD, Naiff RD 1979. Leishmaniasis in Brazil: XIII. Isolation of Leishmania from armadillos (Dasypus novemcinctus) and obsevation on the epidemiology of cutaneous leishmaniasis in north Pará state. Trans $R$ Soc Trop Med Hyg 73: 239-242.

Lainson R, Ward RD, Shaw JJ 1976. Cutaneous leishmaniasis in North Brazil: Lutzomyia anduzei as a major vector. Trans $R$ Soc Trop Med Hyg 70: 171-172.

Martins AV, Silva JE 1964. Notas sobre os flebotomíneos do Estado do Acre, com a descrição de duas espécies novas (Diptera, Psychodidae). Rev Brasil Biol 24: 127-138.

MS - Ministério da Saúde, Secretaria de Vigilância em Saúde, Departamento de Vigilância Epidemiológica 2006. Manual de Vigilância e Controle da Leishmaniose Visceral Americana, Série A, Normas e Manuais Técnicos, $1^{\text {a }}$ ed., Editora do Ministério da Saúde, Brasília, 120 pp.

Pajot FX, Le Pont F, Gentile B, Besnard R 1982. Epidemiology of leishmaniasis in French Guiana. Trans R Soc Trop Med Hyg 76: 112-113.

Rangel EF 1995. Transmission of American Cutaneous Leishmaniasis in peridomestic foci in Rio de Janeiro State and other similar situations compared to the classical epidemiology in Amazon region. Tropical Disease, Society and the Environment, Relatórios de Conferências 2: 103-110.

Rangel EF, Lainson R 2003. Ecologia das Leishmanioses: Transmissores de Leishmaniose Tegumentar Americana. In Flebotomíneos do Brasil. EF Rangel, R Lainson (eds.), Fiocruz, Rio de Janeiro, p. 291-310.

Rangel EF, Lainson R, Souza AA, Ready P, Azevedo ACR 1996. Variation between geographical populations of Lutzomyia (Nyssomyia) whitmani (Antunes \& Coutinho 1939) sensu lato (Diptera: Psychodidae: Phlebotominae) in Brazil. Mem Inst Oswaldo Cruz 91: 43-50.
Ready PD, Lainson R, Shaw JJ, Ward D 1986. The ecology of Lutzomyia umbratilis (Ward \& Fraiha 1977) (Diptera: Psychodidae), the major vector to man of Leishmania braziliensis guyanensis in north-eastern Amazonian Brazil. Bull Ent Res 76: 21-40.

Roberts DR, His BP 1979. An index of species abundance for use with mosquito surveillance data. Environ Entomol 8: 1007-1013.

Shannon CE 1948. A mathematical theory of communication. Bell System Technical Journal 27: 379-423, 623-656.

Silva-Nunes M, Cavasini CE, Silva NS, Galati EAB 2008. Epidemiologia da Leishmaniose Tegumentar e descrição das populações de flebotomíneos no município de Acrelândia, Acre, Brasil. Rev Bras Epidemiol 11: 241-251.

Silveira FT, Souza AAA de, Lainson R, Shaw JJ, Braga RR, Ishikawa EAY 1991. Cutaneous leishmaniasis in the Amazon region, natural infection of the sandfly Lutzomyia ubiquitalis (Psychodidae: Phlebotominae) by Leishmania (Viannia) lainsoni in Pará State, Brazil. Mem Inst Oswaldo Cruz 86: 127-130.

Souza Jr, Veríssimo A, Costa AS, Reis RS, Balieiro C, Ribeiro J 2006 Dinâmica do desmatamento no Estado do Acre (1988-2004). Relatório Técnico do Instituto do Homem e Meio Ambiente da Amazônica, 45 pp.

Tojal AC, Cupolillo E, Volpini AC, Almeida R, Romero GAS 2006. Species diversity causing human cutaneous leishmaniasis in Rio Branco, state of Acre, Brazil. Trop Med Int Health II: 1388-1398.

Tojal AC, Romero GAS, Cupolillo EA 2003. A diversidade das espécies causadoras de leishmaniose cutânea em Rio Branco - Acre. Rev Soc Brasil Med Trop 36 (Suppl. I): 49.

Ward RD, Fraiha H 1977. Lutzomyia umbratilis a new species of sandfly from Brazil (Diptera: Psychodidae). J Med Entomol 14: 3131-3317.

Ward RD, Lainson R, Shaw JJ 1973. Further evidence of the role of Lutzomyia flaviscutellata (Mangabeira) as the vector of Leishmania mexicana amazonensis in Brazil. Trans Roy Soc Trop Med Hyg 67: 608-609.

Young DC, Duncan MA 1994. Guide to the identification and geographic distribution of Lutzomyia sandflies in México, the West Indies, Central and South America (Diptera: Psychodidae). Mem Amer Entomol Inst 54: 1-881. 